\title{
Arap Harfli Türkçe Tıp Yazmaları Çalışmalarında Derleme Sözlüğü'nden Faydalanmak
}

\section{Hakkı ÖZKAYA1}

\begin{abstract}
$\ddot{\mathbf{O} z}$
Arap harfli Türkçe tıp yazmalarında Arapça ve Farsça kökenli sağlık terimlerinin çoğu zaman halk ağzındaki Türkçe karşılıkları da verilir. Bu sağlık terimleri halkın tecrübeleriyle nesilden nesile aktarılarak dile girip yerleşmiş olmalıdır: Yılancık, uyuz, evlek, bıyık bükümü, sıraca, boğmaca gibi. Arap harfli Türkçe tıp yazmalarının söz varlıkları halk ağzında kullanılan birçok sağlık terimini ihtiva etmektedir. Bu nedenle halk ağzında kullanılan sağlık terimlerini ihtiva eden Türkçe tıp yazmaları çalışılırken Derleme Sözlüğ̈̈’nden faydalanmak gerekmektedir. Derleme Sözlüğü taranarak Türkçe sağlık terimlerinin halk ağzındaki kullanım alanlarının tespiti, tespit edilen bu terimlerin tasnif edilerek çeviriyazıya doğru aktarılması sağlık bilgilerinin halka kolayca aktarılabilmesine, tıp öğrenimine ve tıp alanında bilgi üretimine, Arap harfli Türkçe tıp yazmaları çalışmalarına ve bir bilim dili olan Türkçenin zenginliğine önemli katkılar sağlayacaktır. Bu amaçla Derleme Sözlüğü taranmış ve sağlık terimleri ile ilgili olan madde başları tespit edilerek sınıflandırılmıştır.
\end{abstract}

Anahtar kelimeler: Tıp, Türkçe tıp yazmaları, sağlık terimleri, Derleme Sözlüğü.

\section{Making Use of Derleme Sözlüğü (Compilation Dictionary) in the Studies on Turkish Medical Manuscripts in Arabic Alphabet}

\begin{abstract}
Turkish equivalents of medical terms with Arabic and Persian origin can be found in Turkish medical manuscripts written in Arabic alphabet. These medical terms should be transferred from generation to generation basing on the experience of the people, for example: Yılancık, uyuz, evlek, buyık bükümü, straca, boğmaca. The vocabulary of Turkish medical manuscripts written in Arabic alphabet contains many terms on health which are used in colloquial language. Therefore it is necessary to use Derleme Sözlüğü (Compilation Dictionary) while studying on Turkish medical manuscripts. Scanning the Derleme Sözlüğ̈̈, determining the usage area of Turkish medical terms, classification and transcription of them will contribute to transferring knowledge to people, to generating knowledge in medicine, to the studies in Turkish medical manuscripts in Arabic alphabet and to Turkish as a scientific language. For that purpose, Derleme Sözlüğü has been scanned and the entries about medical terms have been determined and classified.
\end{abstract}

Key words: Medicine, Turkish medical manuscripts, medical terms, Derleme Sözlüğü.

\section{Giriş}

Eski Anadolu ve Klasik Osmanlı Türkçeleri dönemlerinde yazılmış olan tıp eserlerinin dili, öğretmeye ve faydaya yönelik bir anlatım ihtiva ettiğinden ağır ve karmaşık bir yapıda değildir; ancak ihtisas metinleri olmaları, ihtiva ettikleri bazı hastalık ve ilaç isimlerinin devrinin literatürüne uygunluk

Dr. Öğrencisi, Marmara Üniversitesi, Türkiyat Araștırmaları Enstitüsü, Türk Dili ve Edebiyatı ABD, Türk Dili Bilim Dalı/ Arş. Gör. Kırklareli Üniversitesi, Fen Edebiyat Fakültesi, Türk Dili ve Edebiyatı Bölümü, ozkayahakki@gmail.com [Makale kayıt tarihi: 9.7.2018-kabul tarihi: 15.8.2018] 
gösterme zaruretini doğurmuş; bu durum, bu isimleri ifade eden kelimelerin Arap ve Fars dillerinin kelime ve terkiplerinden alınmasına yol açmıştır. Bazı kısımlarda, birtakım isimlere karşılık olarak, Yunanca ifadeler de kullanılmıştır. Müellif veya müstensihler, bunların birçoğunun ya Türkçe karşılıklarını vermiş veyahut tariflerini ve özelliklerini izah etmeye çalışmıştır. (Ünver, 1983, s. 10) Bu durum da günümüz okuru ve araştırmacısı için tamamen farklı bir söz varlığı demektir.

Ayrıca, bu dönemde kullanılan Arap alfabesi, Türkçedeki her sesi karşılayamamakta; metnin okunması, fonetik ve morfolojik yapısının incelenmesi imlâ özelliklerinin dikkatli bir şekilde incelenmesine bağlı olmaktadır. Metinlerdeki bazı imlâ farklılıklarının, müstensihin bilgisi veya dikkatiyle de alakalı olması ihtimali mevcuttur. (Kâhya, 1992, s. 93) Özellikle "b", "c", "ç", "p", seslerinin yazılışında bu farklar daha açık görülebilmektedir. Ünlüler bakımından da, tutarlılık olduğunu söylemek zordur. Harekeler, dikkatlice yerlerine konmadığı ve şekilleri açıç̧a belli olmadığı için ünlüleri değerlendirmede bazı zorluklarla karşılaşılmıştır. Çoğu kez kelime içeresindeki 'a' ve 'e' ünlüleri birbirlerinden ayrılmamıştır. Bazı kelimelerde hem 'e' hem 'i' ünlüsü bulunduran şekiller vardır: Geç, giç; gece, gice; ye-, yi-; gibi. Bu durum esere bazı ağız özelliklerinin karıştığı ihtimalini doğurmaktadır. Aynı zamanda kapalı e vokalinin harekelenmesinde standartın sağlanamadığı anlaşılmaktadır. Bu durum da günümüz ilgili okuru veya ilgili alan araştırmacısı için aşması gereken bir durumdur. Biz de Eski Anadolu ve Klasik Osmanlı Türkçeleri dönemlerinde yazılmış tıp metinlerindeki sağlık terimlerinin doğru okunup sağlam bir dil içi çeviri yapılması adına Derleme Sözlüğ̈̈’nde yer alan mezkur dönemlerle ilgili bazı tıp terimlerini bulup sayfa sayısı vererek tasnifledik.

\section{A ̆ğı Terimleri}

ağız eskisi Ağız ağrısı, bir çeşit ağız yarası. (DS, s 96)

ağrı [ağarma, ağır hastalık, ağırma, ağrıter] 1. Soğuktan ileri gelen bir çeşit hastalık. 2. Yara, çıban gibi hastalıklara verilen ad. (DS, s 109)

ağrık 1. Ağrı, sancı, yel. 2. Hastalık. (DS, s 110)

avsın 1. Hayvan sokmalarının zehir ve ağrısını tesirsiz kılmak için yapılan işlem. (DS, s 392)

bağırca Göğüs ağrısı, yürek ağrısı. (DS, s 4440)

balkı Sancı, ağrı, sızı. (DS, s 507)

batan Zatürree ve zatülcenp hastalıklarında göğüste ve sırtta hissedilen ağrı. (DS, s 569)

batar [batak] Sancı, ağrı (daha çok göğüs ve karın ağrısı). (DS, s 569)

belez Sizı, ağrı. (DS, s 616)

bögr ağrısı Karın ağrısı. (DS, s 758)

burç Karın ağrısı. (DS, s 795)

burgu Diş ağrısı. (DS, s 797)

butur Omuz ağrısı, kulunç. (DS, s 806) 
büklesin Göbek kaçılı̆ı̆ından ileri gelen ve bükülünce geçeceği sanılan bir çeşit karın ağrısı. (DS, s 817) coz Göz ağrısı. (DS, s 1004)

çevrenmek Baş ağrımak. (DS, s 1154)

çiğsimek Vücudun bir yeri ağrımak, sızlamak. (DS, s 1211)

çömelek Hafif ve ince ağrı, sızı. (DS, s 1286)

dolukmaq Koşmaktan, yorgunluktan vücudun bir yeri ağrımak. (DS, s 1547)

döğün Bacaktaki ağrııı gidermek için nohut yakısı ile açılan yara. (DS, s 1572)

enme 1. Bademcik iltihabı. 2. Sancı, ağrı. (DS, s 1759)

et kesiği Adale ağrısı. (DS, s 4499)

evtinmek Hastalığın verdiği ağrı, sızı ve acı ile kıvranmak, herhangi bir yeri didiklemek. (DS, s 1817)

furtatmak Damar damar üstüne binmek ve ağrı yapmak. (DS, s 1857)

garnegirsi Karın ağrısı. (DS, s 1929)

girme Başın bir tarafında olan ağrı. (DS, s 2085)

hamlamaq Vücudun her yeri ağrıyıp zonklamak. (DS, s 2267)

hiçik Göz ağrısı. (DS, s 2383)

ı̆̆ım Dert, hastalık, ağrı, sızı. (DS, s 2456)

imik garıncalanmak Boğaz ağrımak. (DS, s 2536)

innağ olmak Çocukların boğazı ağrımak. (DS, s 2544)

kannama Karın ağrısı, bağırsak gazı. (DS, s 2626)

karadamla Birdenbire vücudu kaplayan ağrı. (DS, s 2641)

karasalgın 1. Dişlerdeki iskorpit hastalığı. 2. Boğaz ağrısı. (DS, s 2652)

karıkmak [kardı olmak, karık değmek, karıklamak, karılmak] Güneyli havada kara bakmaktan göz ağrımak. (DS, s 2662)

karın kavraması [karın kıstı] Karın ağrısı. (DS, s 2663)

kavramak [kavrımak] Sancılanmak, ağrımak. (DS, s 2691)

keleplenmek Sancıdan, ağrıdan kıvranmak. (DS, s 2729) 
kengi 1. Romatizma. 2. Lumbago. 3. Nezle. 4. Firengi. 5. Ağrı, sızı. (DS, s 2743)

kıldırık olmak [kıldurmak] Kadın memesi süt birikmesi nedeniyle ağrımak. (DS, s 2796)

lopulmak İrinlenmiş yara sancımak, ağrımak. (DS, s 4580)

melas [meras] Genellikle ellerde ve ayaklarda beliren ağrllı tutukluk, kramp. (DS, s 3153)

meytambal Kulak ağrısı. (DS, s 3175)

parabaş olmak Yarım baş ağrısına tutulmak. (DS, s 3394)

seklem olmak Her yanı ağrımak. (DS, s 3571)

sırgı Baş ağrısı. (DS, s 3615)

sırğı Diş nezlesi, diş ağrısı. (DS, s 3615)

şakı Baş ağrısı. (DS, s 3735)

şoran Yara nedeniyle, yakındaki bezelerin şişliği, ağrısı. (DS, s 3791)

tatacan Sancl, ağrı. (DS, s 3842)

tatarca [tatarcık, tatarham, tatarhamı, tatarqamu, tatarqan] Şiddetli karın ağrısı. (DS, s 3842)

tatarca Böbrek ağrısı. (DS, s 3842)

tığlamak Yara çok ağrımak. (DS, s 3908)

tilçi Sızlanan, ağrısı, sancısı olan, yakınan. (DS, s 3931)

tokma Çok yemekten olan mide ağrısı. (DS, s 3949)

topalan Hazımsızlıktan ileri gelen mide ve karın ağrısı. (DS, s 3962)

tutarca Karın ağrısı. (DS, s 3999)

yakı 1. Karın ağrısı. 2. Sürgün, ishal. (DS, s 4128)

yarımca Yarım baş ağrısı. (DS, s 4184)

\section{Tedavi Terimleri}

avsın 1. Hayvan sokmalarının zehir ve ağrısını tesirsiz kılmak için yapılan işlem. (DS, s 392)

diliceğini kaldırmak Anjin olan bir kimsenin boğazını yukarıya kaldırarak tedavi etmek (Halk hekimliğinde). (DS, s 1493) 
parpı [parpu] Hastalanan insan ya da hayvanları, ocak denilen kimselerce, ev ilaçlarıyla ve okuyarak iyileştirme işlemi. (DS, s 3398)

parpılanmak 1. Kızgın demirle dağlanmak. 2. Hasta halk hekimlerince okunup üflenerek, ilaçlanarak iyileştirilmek. (DS, s 3399)

parpılatmak Hasta çocukları okutup üfletmek. (DS, s 3400)

parpullamak Hastayı ev ilaçlarıyla ve okuyup üfleyerek, kurşun dökerek, yarayı dağlayarak iyileştirmeye çalışmak (ocak denilen halk hekimlerince). (DS, s 3400)

urasa [uğrasa] 1. Hastalığa, cine, periye karşı okuyup üfleme, afsunlama. 2. Hastalığı, kocakarı ilaçlarıyla sağaltma çabası, işi. (DS, s 4040)

\section{Aletler ile İlgili Terimler}

çırpan Sarılığın tedavisinde kullanılan bir alet. (DS, s 1189)

çölme Baş ağrıdığı zaman alna bağlanan ince eşarp veya örtü gibi şeyler. (DS, s 1283)

gisğaç Kerpeten, pense vb. aletler. (DS, s 2062)

gödele Cendere gibi sıkıştıran alet. (DS, s 2124)

farç İnce ve düz taş: Bir farç ısıt da karnına koy, ağrısı geçer. (DS, s 1834)

kaskesti Başı ağrıyan kimsenin alnına bağladığı bă̆. (DS, s 2675)

kengir Kepçe. (DS, s 2743)

şekik Baş ağrısına iyi geldiği sanılan taş. (DS, s 3757)

\section{Ölçü Terimleri}

ağızlık [ağız taşı] Su için ölçü birimi. (DS, s 98)

alım 1. Pekmez kaynatılan tava veya kazanın ölçüsü: Senin bağdan iki alımlık pekmez olur. 2. Genişlik, hacim: Bir çuvalın alımı fazla. (DS, s 217)

ayar 1. Bir tahıl ölçüsü. 2. Fındık taşımaya yarıyan orta boy sepet. 3. Bir zeytinyağı ölçü birimi ve kabı. (DS, s 407)

baş başı Ölçüde, tartıda tahminin üstünde çıkan kısım. (DS, s 549)

batam [batmon] Miktarı yer yer değişen eski bir ağırlık ölçüsü, batman. (DS, s 569)

belevurt etmek [belevürt etmek] Ölçüp karşılaştırmak. (DS, s 616)

bidemi Arşın kadar bir ölçü. (DS, s 684) 
bitimi ölçü Yüz dirhem. (DS, s 711)

buçuk [buçuklağa, buçuklağı]1. Yüzatmış gramlık bir ağırlık ölçüsü. 2. İkiyüzelli gramlık bir ağırlık ölçüsü. 3. Üçyüz gramlık bir ağırlık ölçüsü. 4. Yarım kilelik ölçü. (DS, s 777)

buçuklağı 1.Yarım batman (7.697 kg.lık eski bir ölçü) sıvı alan bakır kova, kap. 2. 5.052 litre su alan kap. (DS, s 777)

büyük mut Tahıl ölçüsü (18 gazyağı tenekesi). (DS, s 832)

cara Bakırdan yapılmış, on iki, on üç litrelik zeytinyağı ölçüsü. (DS, s 859)

çap Tahıl ölçeği. (DS, s 1072)

çeki [çekü ] Ağırlık ölçüsü (1 kg.). (DS, s 1112)

çekü Tüfekte barut ve saçma miktarını gösteren ölçü. (DS, s 1112)

çenge Parmaklar aşağı doğru olarak elin alabileceği ölçüde, avuç dolusu. (DS, s 4477)

çerik [cerik] Altı kiloluk bir çeşit hububat ölçüsü. (DS, s 1146)

çıtır Hububat ölçüsü, kile. (DS, s 1194)

çinik [canak, cinik] Sekiz kiloluk bir hububat ölçüsü, şinik. (DS, s 1228)

çiplik Baş ve işaret parmaklarının arasındaki açıklıktan ibaret olan bir ölçü. (DS, s 1234)

direk Yirmibeş ile kırk şinik arasında değişen ve tohum ölçmeye yarayan ölçü. (DS, s 1512)

direm 1. Bir ağırlık ölçüsü, dirhem. 2. Azıcık, bir parça. (DS, s 1513)

dönek Eni ve boyu kırkar arşın olan bir yüzey ölçüsü, dönüm. (DS, s 1583)

dördüllükk Hacim ölçüsü, küp. (DS, s 1587)

evlek On kiloluk tahıl ölçüsü. (DS, s 1810)

fitre Gaz tenekesinin sekizde biri ölçüsünde. (DS, s 4505)

got Tahıl ölçüsü. (DS, s 2108)

gödük On iki ya da on beş okkalık eski bir tahıl ölçüsü. (DS, s 2126)

gurik Tahıl ölçüsü. (DS, s 2198)

gülek [gülgülü , gülk ] Ağaçtan yapılmış kap (süt, yağ, vb. konulur). (DS, s 2218)

gülk Bir tahıl ölçüsü. (DS, s 2219) 
halebi [helebi, qelevi] Altmışbeş santimetre boyunda bir uzunluk ölçüsü, arşın. (DS, s 2259)

hanayı Tahıl ölçü birimleri. (DS, s 4514)

ı̆̆aç Eskiden kullanılan bir çeşit uzunluk ölçüsü, fersah. (DS, s 2456)

llgıdır Bir uzunluk ölçüsü, arşın. (DS, s 2468)

iğaç Aşağı yukarı beş kilometrelik uzaklık ölçüsü, fersah. (DS, s 2509)

kabak Kilenin 1/16 ölçüsünde bir tahıl ölçeği. (DS, s 2578)

kadak Üç tanesi bir okka olan ağırlık ölçüsü. (DS, s 2588)

kapçiyek Tahtadan yapılmış bir kiloluk tahıl ölçüsü. (DS, s 2632)

kavas Buğday ölçülen şinik. (DS, s 2687)

kel Yarım (ağırlık ölçüsü için). (DS, s 2724)

kıvranka Ağırlık ölçüleri. (DS, s 2852)

kıvrat Ölçü, ayar (altın vb. için). (DS, s 2853)

kutla [kutu ] 1. On iki okkalık, ağaçtan yapılmış tahıl ölçeği, şinik. 2. Yarım kile. (DS, s 3017)

kutu Yirmi okkalık ölçü kabı. (DS, s 3017)

nimenim Eski bir ağırlık ölçüsü, yirmi beş dirhem. (DS, s 3251)

nû Bir ağırlık ölçüsü, dirhem. (DS, s 3256)

nüğü İki yüz dirhemlik ağırlı ölçüsü, yarım okka. (DS, s 3257)

önge Elli dirhem (eski bir ağırlık ölçüsü). (DS, s 3339)

önke Yüz dirhem (eski bir ağırlık ölçüsü). (DS, s 3340)

pitemi Yarım metre boyunda bir uzunluk ölçüsü. (DS, s 3463)

put On altı kg.lık ağırlık ölçüsü. (DS, s 3492)

salgan 1. Tahıl yıkamak için derenin çukur yerine yerleştirilen çul, kilim. 2. Yıkamak için çukura yerleştirilen çulun aldı̆̆ı ölçüde tahıl. (DS, s 4665)

sere Başparmakla işaret parmağı arasındaki uzaklık (ölçü için). (DS, s 3586)

Sırım Dönümden küçük toprak ölçüsü. (DS, s 3616)

somar 1. On sekiz okka alan ölçekle on altı kez ölçülmüş tahıl. 2. Mısır ölçeği. (DS, s 3662) 
süğlüç [süğüş, sümgüç, sümüş] Baş ve işaret parmaklarının gergin açllmasıyla oluşan ölçü. (DS, s 3705)

süyem [süyüm] El ölçüsü, karış. (DS, s 3728)

tak Bahçe sulama için ölçü birimi, kez. (DS, s 4733)

tar Gübre ve kül ölçüsü olarak kullanılan çuval. (DS, s 3830)

tırıb Ölçü. (DS, s 4760)

toht Yüzatmış gramlık ağırlık ölçüsü. (DS, s 3945)

tuht Elli dirhemlik eski bir ağırlık ölçüsü (bir dirhem 31 desigrama eşittir). (DS, s 3987)

yarımlâ Yarım kilelik tahıl ölçü birimi. (DS, s 4184)

yarımlağı Dörtte bir kile oylumunda tahıl ölçü birimi. (DS, s 4184)

yarımlık 1. Şinik denilen tahıl ölçü biriminin yarısı. 2. Şinik denilen tahıl ölçü biriminin dörtte biri. (DS, s 4184)

yığma Ceviz, badem vb. satılırken, taşırarak doldurulan ölçü. (DS, s 4263)

yuvak 1. Parça. 2. Ölçü birimi. (DS, s 4826)

\section{Hastalık Terimleri}

ağrı [ağarma, ağır hastalık, ağırma, ağrıter] 1. Soğuktan ileri gelen bir çeşit hastalık. 2. Yara, çıban gibi hastalıklara verilen ad. (DS, s 109)

ağrıcak Gözde sürekli çapak yapan bir göz hastalı̆̆ı. (DS, s 109)

at ağrısı Sancı yapan ve göğsü dağlayarak geçirilen bir çeşit at hastalı̆̆ı. (DS, s 364)

bajala Beş-altı aylık çocuklarda görülen bir hastalık ki, çocukların karnı ağrır. (DS, s 489)

baz 1. Vücut. 2. Bir yara dolayısiyle şişen bacak arasındaki ve koltuk altındaki bezler. (DS, s 585)

béz Deri altında yara vb. nedenlerle oluşan ağrılı şişkinlik. (DS, s 4456)

haukmak Yara azmak. (DS, s 2307)

hökel Baş ağrısı ile başlayan nezle hastalığı. (DS, s 2429)

karagöynük Soğuktan vücudun her yarımda olan ve ağrı yapan şişler. (DS, s 2643)

kılkabar Çoğu zaman parmak uçlarında görülen, ağrısı çok şiddetli bir çeşit kabarık yara. (DS, s 2799)

kötü yara [kötü ağrı] Firengi. (DS, s 2983) 
kötüce Nezle. (DS, s 2982)

morca Genellikle sonbaharda çıan ağrılı bir çıban. (DS, s 3210)

orta ağrısı Salgın hastalık. (DS, s 4615)

ortalık ağrısı Bulaşıcı hastalık. (DS, s 3289)

tatarkurdu Karında şiddetli ağrı yapan bir çeşit at hastalığı. (DS, s 3843)

uluk İnce, narin, hastalıklı. (DS, s 4034)

yakarca Zona da denilen, deride oluşan, ağrılı, kaşıntılı kabarcıklar. (DS, s 4809)

yelyuva İnsanda, hayvanda görülen, ağrısız büyüyen şişlik. (DS, s 4241)

ziknimek Hastalık, ağrı azalmak. (DS, s 4386)

\section{Bitki Terimleri}

acı yavşan Yavşan otu, veronica denilen ve kaynamış suyu ağrılara ilâç olarak kullanılan bir bitki. (DS, s 54)

ağa düğü Karın ağrısına ilâç olarak kullanılan sarı bir ot. (DS, s 89)

akyavşan Karın ağrılarında ilâç olarak kullanılan bir çeşit kokulu ot, acı yavşan. (DS, s 165)

batbit otu Küçük siyah torbacıklar içinde, kırmızı tohumları olan ve diş ağrılarına karşı ilâç olarak kullanılan bir bitki. (DS, s 570)

eğir Karın ağrısına karşı kullanılan bir çeşit kök. (DS, s 1678)

eldüren Kaynatılıp ağrıyan yerlere, sıcak sıcak sarılmak suretiyle, halk arasında ilâç olarak kullanılan bir çeşit bitki. (DS, s 1709)

enlik 1. Boyacılıkta kullanılan bir çeşit ot. 2. Yağ ya da balmumu ile karıştırılarak merhem yapılan bir çeşit ot. (DS, s 1759)

éşkın [eşkin] Kenger, kangal vb. bitkilerde gövdede oluşan sürgünler. (DS, s 1793)

gara ot Şiddetli ağrılara ilâç için kullanılan bir çeşit ot. (DS, s 1921)

gelemağrı [gelemari galeni ağrı] Bir çeşit ayrık otu. (DS, s 1974)

hamıza Kökünden çıkarılan sütü, karın ağrısı ve sıtmaya iyi gelen, karpuz yaprağına benzer yaprakları olan bir çeşit bitki. (DS, s 2267)

hevecive Kökü kaynatılarak kırmızı bir merhem elde edilen ve yaralara iyi gelen bir çeşit bitki, havacıva. (DS, s 2350) 
hölebeș Hekimlikte kullanılan hodan bitkisinin tomurcukları. (DS, s 2430)

Işkın -1 Kayalık yerlerde ve dağlarda yetişen, yenilebilir bir çeşit ot. (DS, s 2494)

Işkın -2 Karabuğdaygillerden, hekimlikte kullanılan bir çeşit bitki, Rheum Polygonaceae. (DS, s 2495)

ilâbada Sı̆̆ırdili familyasından, çiçekleri hekimlikte kullanılan ve kökü kavrularak yenilen bir bitki. (DS, s 2517)

işşek burgacanı Mavi çiçek açan, beyaz renkli bir çeşit ot. (DS, s 2555)

işşek turpu Karın ağrısına iyi gelen, turp gibi acı bir çeşit ot. (DS, s 2556)

karacaot Kökü hayvanların vücutlarındaki ağrı ve sızıyı gidermekte kullanılan bir ot. (DS, s 2639)

karıngeveni Karın ağrısında kullanılan, dağlarda biten bir bitki. (DS, s 2663)

kengi otu [kengel] Eşek dikeni denilen, kırlarda biten, kökünden süt çıkan, dikenli bir ot, kenger. (DS, s 2743)

kıngıra otu Baş ağrısını iyileştirmekte kullanılan bir çeşit ot (ağrının geçmesi için bu otla burunlarını kanatırlar). (DS, s 2810)

köpekcevizi Tohumu baş ağrısı için koklunun bir çeşit bitki. (DS, s 2960)

mantuvar [mantıvar, mantüvar] Kulak ağrısını geçirmek için kullanılan, çiçekleri güzel kokulu ve sarı renkli bir kır bitkisi. (DS, s 3126)

mumurhan [mumlığan, mumuhan, mumuran, mumurgan] Balmumu, zeytinyağı, bademyağı, limon, mezdeki karıştırılarak yapılan ve deri hastalığının iyileştirilmesinde kullanılan merhem. (DS, s 3219)

oğlanotu Ağız ve karın ağrılarını geçirmek için kullanılan bir çeşit yabanıl ot. (DS, s 3268)

öğlanotu Dağlarda yetişen, ilaç yapmakta kullanılan, boz renkli bir ot. (DS, s 3316)

pelüm [pelun] Halk hekimliğinde kullanılan bir bitki, pelin. (DS, s 3425)

tarhın [tarakotu] Hekimlikte kullanılan ıtırlı bir bitki. (DS, s 3833)

tatala 1. Bayırlarda yetişen, yüzük biçiminde bir çeşit ot. 2. Yendiği zaman insanı rahatlatan, hekimlikte kullanılan yabanıl bir ot. (DS, s 3842)

tatlımiyan [tatlıbayram, tatlıbiyan, tatlıkökü] Toprak altında kalan bölümü hekimlikte kullanılan, iki çenekli, kapalıtohumlulardan bir çeşit küçük ağaç. (DS, s 3844)

tercan 1. Kırmızı buğday. 2. Yazan yemek için ayrılan buğday. (DS, s 3888)

tutya Mor renkli, kokulu bir kır çiçeği. (DS, s 4002) 
yalotu Kurutulup ufalanarak, ilaç olarak kullanılan, sarmaşık biçiminde bir ot. (DS, s 4149)

yelmeşük otu Sancı, ağrı gidermede ve tahtakurularına karşı kullanılan bir ot. (DS, s 4238)

zimbilaçı Devedikeni. (DS, s 4387)

\section{İlaç Terimleri}

acıca Karın ağrısına iyi gelen kekik veya filiskin (Mentha Silvestris) suyu. (DS, s 45)

azva Karamuk ağacının kökünden çıkarılan ve göz ağrılarını iyileştirmede kullanılan bir sıvı. (DS, s 443)

azvay Ekşi yapraklı bir çeşit çalı kökünden kaynatılarak yapılan, göz ağrılarına iyi gelen em. (DS, s 443)

ballama Karın ağrısını geçirmek için bal ve kuru nane karıştırılarak yapılan kocakarı ilâcı. (DS, s 509)

bıngı Açılmamış çıban ağrısını dindirmek için yapılan ilâç. (DS, s 667)

buçuklağı 1.Yarım batman (7.697 kg.lık eski bir ölçü) sıvı alan bakır kova, kap. 2. 5.052 litre su alan kap. (DS, s 777)

cıbar [cıhar, cibar] Bel ağrılarında, kırık ve çıkık tedavisinde kullanılan iç yağı ve karasakız karışımı yakı. (DS, s 889)

cihar Vücut ağrılarını geçirmekte kullanılan, beze sürülmüş kara sakız. (DS, s 963)

dolaz Çentilmiş sabunu yumurta akı ya da süt ile karıştırarak yapılan ve yaraların tedavisinde kullanılan bir çeşit merhem. (DS, s 1545)

döyüm Yara açıcı ottan yapılan bir çeşit ilaç. (DS, s 1594)

eğil Çocukların karın ağrılarını geçirmek için kullanılan bir çeşit beyaz baharat. (DS, s 1678)

enekmene Tarlalarda yetişen bir bitkinin kökünde bulunan kırmızı yumruların yağda eritilmesiyle yaplan merhem. (DS, s 1749)

enlikli em Sadeyağ, balmumu ve enlik denilen bitki yaprağının karıştırılması ile yapılan merhem. (DS, s 1759)

kengir [kengel] Dikenli bir otun kökünden alınan sakız. (DS, s 2743)

kurum Merhem, em. (DS, s 3012)

küveki Boğaz ağrılarında kullanılan bir çeşit em. (DS, s 4579)

lapuğa Şiş ya da ağriyan yerlere konulan lapa. (DS, s 3066)

lökün 1. Yumurta akı, sabun, zeytinyağı ile yapılan ve kırık çıkıkların iyileştirilmesinde kullanılan bir çeşit ilâç. 2. Sabun ve yumurta ile yapılıp ağrıyan yere yapıştırılan yakı. (DS, s 3089) 
maht Arıyı kovana alıştırmak için yapılan ilaç. (DS, s 3106)

ökse Asmalara dadanan bir hastalığa karşı kullanılan ilaç. (DS, s 3326)

posata Bağlara, üzümlerin bozulmaması için saçllan ilaç. (DS, s 3472)

tefal Em, ilaç, umar. (DS, s 4745)

tutya Göz ağrllarına iyi gelen, sürme gibi göze çekilen bir em. (DS, s 4002)

uluk Emsiz, ilaçsız. (DS, s 4784)

yağlı kara 1. İsle yağ karışımından oluşan, halk arasında yaralara da sürülen tencere kiri. 2. Yanmış bez artığının, yağla karışımından yapılan bir merhem. (DS, s 4123)

\section{Hekimlik Terimleri}

olçum Doktor. (DS, s 3277)

ölçüm Hekimlik taslayan, yıldızların hareketinden sonuç çıkaran. (DS, s 3330)

parpıcı [parpulcu] Hastalığı okuyarak, ev ilaçlarıyla iyileştiren halk hekimi, ocak. (DS, s 3398)

\section{Sonuç}

Arap harfli Türkçe tıp yazmaları çalışmalarında dikkatimizi çeken en önemli hususlardan birisi, Arapça ve Farsça olan hastalık ve deva kelimelerinin çeviriyazılarında sorun olmadığı, bu kelimelerin yerine konacak Türkçe kelimelerin çeviriyazılarında bir karmaşa yaşanmış olduğudur.

Çalışmalarımız esnasında fark ettiğimiz bir husus da, Eski Anadolu ve Klasik Osmanlı Türkçesi dönemleriyle ilgili tematik lügat bulmaktaki zorluktur. Her ne kadar Derleme Sözlüğü ve Tarama Sözlüğü varsa da, dönemin tıbbi eserleri yeniden taranarak müstakil bir sözlük hazırlanması gerektiğini düşünmekteyiz. Ayrıca neşredilen bazı Arap harfli tıp metinlerinin söz varlıklarında, fonetik ve morfolojik olarak farklar bulunmakta, bazı kelimeler birden fazla şekillerle metinlerde yer almaktadırlar. Derleme Sözlüğü’nden yaptığımız bu tasnifle bir birliktelik ortaya çıkabilir.

Eski Anadolu ve Klasik Osmanlı Türkçesi dönemlerinden günümüze kadar ulaşabilen yazmaların incelenmesi hem tıp, hem de dil tarihimiz açısından faydalı olacak, her iki ilim dalının günümüze uzanabilecek bilgi unsurları, eski ile yeni eserler arasında kültür köprüsünün kurulmasını sağlayabilecektir.

\section{Kaynakça}

Bayat, A. H. (2016). Trp Tarihi. İstanbul: Zeytinburnu Belediyesi Kültür Yay.

Derleme Sözlüğü c. I-XI. (1963-1982). Ankara: TDK Yayınları.

Doğan, Ş., \& Güneş, S. (2014). "Bir Eski Oğuz Türkçesi Metni: Risâle-i Bevâsîr". Türük Uluslararası Dil, Edebiyat ve Halkbilimi Araşttrmaları Dergisi,, 53-117.

Kâhya, E. (1992). Onbeşinci Yüzyılda Yaşamış, Bir Hekimimiz Mümin B. Mukbil, I. Türk Tıp Tarihi Kongresi Bildirileri. Ankara: Türk Tarih Kurumu Basımevi. 
Kültüral, Z., \& Koç, A. (2012). Derviş Muhammed bin eş-Şeyh el-Ankaravi, Durrü’l-Meknûn (sakh İnciler), Giriş-Metin-Dizin-Tipkıbasım. Konya: Palet Yayınları.

Ünver, S. (1983). Tip Tarihi Yillı̆̆ II. İstanbul.

Zülfikar-Aydın, M. B. (1998). 18. yüzyıla Ait Türkçe "Müfredat" Kitapları ve Türk Tarihindeki Yeri. Tzp Tarihi Araşttrmaları, 55-168. 